2. Brilakis ES, Olson LJ, Berry GJ, et al. Survival outcomes of patients with giant cell myocarditis bridged by ventricular assist devices. ASAIO J. 2000;46:569-72.

3. Chen JM, Spanier TB, Gonzalez JJ, et al. Improved survival in patients with acute myocarditis using external pulsatile mechanical ventricular assistance. J Heart Lung Transplant. 1999;18:351-7.

4. Davidoff R, Palacios I, Sothern J, Fallon JT, Newell J, Dec GW. Giant cell versus lymphocytic myocarditis. A comparison of their clinical features and long-term outcomes. Circulation. 1991;83:953-61.

5. Litovski SH, Burke AP, Virmani R. Giant cell myocarditis: an entity distinct from sarcoidosis characterized by multiphasic myocyte destruction by cytotoxic T cells and histiocytic giant cells. Mod Pathol. 1996;9:1126-34.

6. Ankersmith HJ, Wieselthaler GA, Moser B, et al. Automated implantable cardiac defibrillator and biventricular Thoratec assist device as bridge to transplantation in a patient with sarcoidosis. J Thorac Cardiovasc Surg. 2001;121:1198-9.
7. Lemery R, McGoon MD, Edwards WD. Cardiac sarcoidosis: a potentially treatable form of myocarditis. Mayo Clin Proc. 1985;60:549-54.

8. Tarantini G, Menti L, Angelini A, Martini B, Thiene G, Daliento L. Life-threatening ventricular arrhythmias associated with giant cell myocarditis (possibly sarcoidosis). Am J Cardiol. 2000;85:1280-2.

9. Gibbs AR, Williams WJ, Kelland D. Necrotising sarcoid granulomatosis: a problem of identity. A study of seven cases. Sarcoidosis. 1987;4:94-100.

10. Bartling B, Milting H, Schumann H, et al. Myocardial gene expression of regulators of myocyte apoptosis and myocyte calcium homeostasis during hemodynamic unloading by ventricular assist devices in patients with end-stage heart failure. Circulation. 1999;100(Suppl II): 216-23.

11. Jett GK, Miller A, Savino D, Gonwa T. Reversal of acute fulminant lymphocytic myocarditis with combined technology of OKT3 monoclonal antibody and mechanical circulatory support. J Heart Lung Transplant. 1992;11:733-8.

\title{
Intraparenchymal replacement of the left pulmonary artery with implantation of segmental arteries in a 26-year-old patient
}

Niyazi Cebi, MD, Frömke Johannes, MD, Spiridon Botsios, MD, and Gerd Walterbusch, MD, Dortmund, Germany

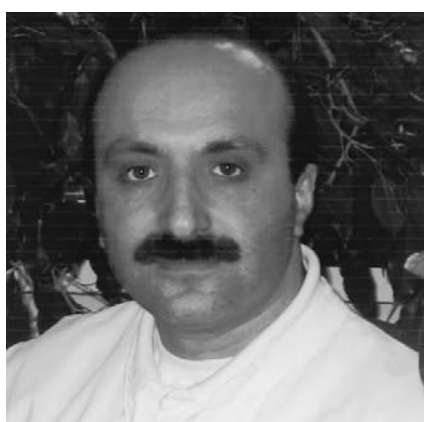

Dr Cebi

A neurysms of the pulmonary artery are associated with primary or secondary pulmonary hypertension, ${ }^{1}$ chronic pulmonary embolism, or pulmonary valve stenosis. $^{2}$ Systemic disorders, such as Behçet disease, ${ }^{3}$ Osler disease, and other acquired cardiovascular or congenital diseases, ${ }^{4}$ are known to produce such aneurysms. Lethal complications include bronchial rupture, ${ }^{3,4}$ dissections, and intrapulmonary erosion. Compression of neighboring structures is also a source of morbidity. We report on a patient who was referred to our hospital after demonstration of bilateral, dilative changes of the segmental arteries of the apicoposterior segments of the upper lobes, as well as an aneurysm of the left pulmonary artery of $3 \mathrm{~cm}$ in diameter at the bronchial bifurcation of the upper and lower lobes (Figure 1). Additional aneurysms, including those in the right lower lobe branches, were also observed. The surgical

From the Department of Thoracic and Cardiovascular Surgery, St-Johannes-Hospital Dortmund, Dortmund, Germany.

Received for publication May 7, 2003; accepted for publication May 28, 2003.

Address for reprints: Niyazi Cebi, MD, Schondellestr. 19b, 44229 Dortmund, Germany (E-mail: niyazi@destur.de).

J Thorac Cardiovasc Surg 2003;126:2074-7

Copyright $(2003$ by The American Association for Thoracic Surgery $0022-5223 / 2003 \$ 30.00+0$

doi:10.1016/S0022-5223(03)00932-2

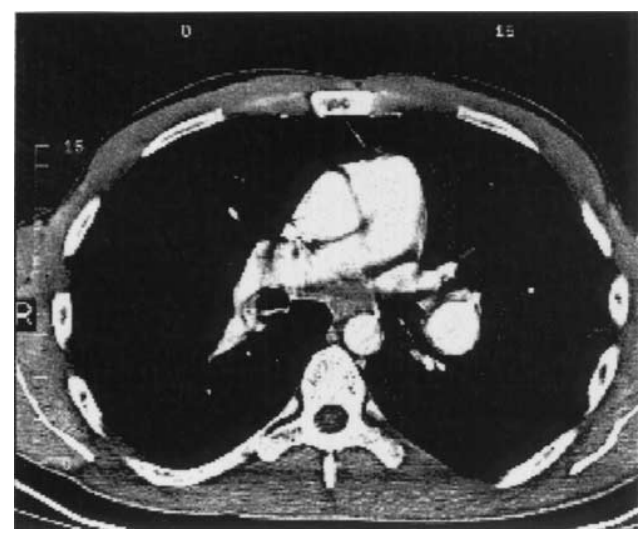

Figure 1. Computed tomographic scan demonstrating aneurysm of the left pulmonary artery at the bronchial bifurcation of the upper and lower lobes.

procedure is discussed and described as a new lung parenchymasparing technique.

\section{Methods}

A 26-year-old patient with confirmed Behçet disease and a weeklong history of hemoptysis was admitted to our hospital. The patient had previously undergone treatment for uveitis and oral and genital ulceration. A portion of the small intestine had also been 


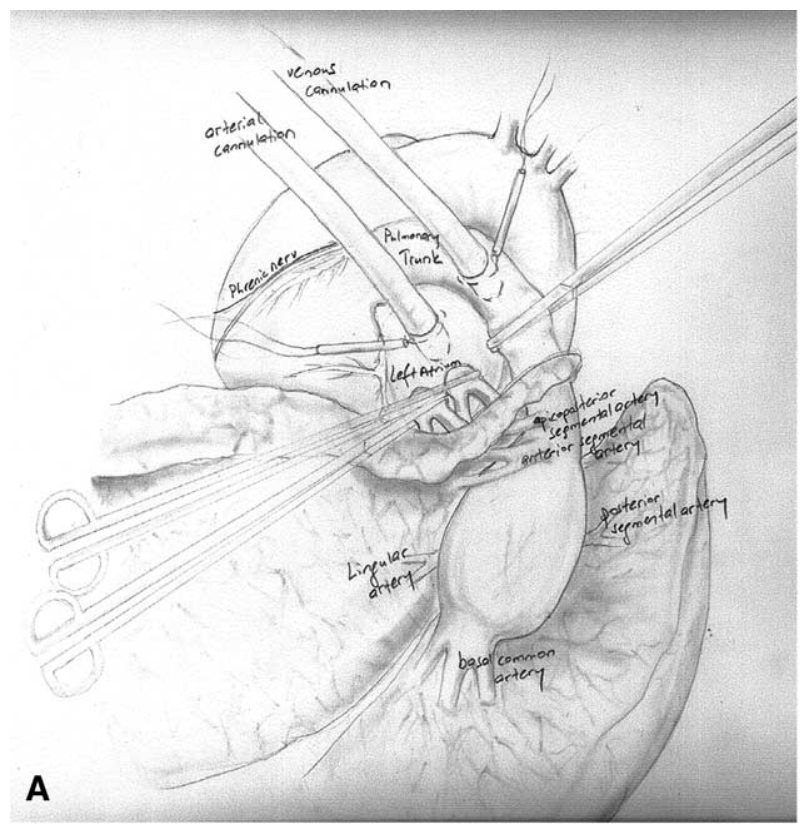

Figure 2A. Demonstration of the extension of the left pulmonary artery aneurysm.

resected because of idiopathic inflammation and perforation. This history is typical for Behçet disease, in which aneurysms of the elastic pulmonary artery are caused by lymphocytic necrotizing vasculitis. ${ }^{5}$ Medical treatment consisted of prednisone and azathioprine.

The aneurysmatic changes were demonstrated by computed tomography. Bronchoscopy revealed bloody imbibitions and changes in the bronchial mucous membranes of the lingula and lower lobe. Emergency surgical intervention was indicated. The pulmonary hilus and left pulmonary artery were exposed and prepared for clamping through a left posterolateral thoracotomy. The pericardium was incised posterior to the phrenic nerve, and the left pulmonary veins were prepared and clamped. Access to the aneurysm was gained through the main pulmonary fissure. After occlusion of the left pulmonary artery, invasive pressure measurements demonstrated values of $25 \mathrm{~mm} \mathrm{Hg}$. Because the aneurysm was still partially perfused, partial bypass by use of the extracorporeal circulation was established by means of pulmonary trunk and left atrial cannulation. After incision of the aneurysm of the left pulmonary artery, the continued backflow came from the ostia of the segmental arteries of the left lung. The replacement of the left pulmonary artery was performed during continuous aspiration of back bleeding to the extracorporal circulation. The aneurysm of the left pulmonary artery extended from immediately below the anterior and apicoposterior segmental arteries of the left upper lobe down to the bifurcation of the segmental arteries of the left lower lobe. Detailed descriptions of the operative techniques were shown in Figures 2A, 2B, and 2C. A vascular graft was constructed with an $8 \times 4-\mathrm{cm}$ heterologous pericardial patch (Supple Peri-Guard; Bio-Vascular Inc, St Paul, Minn; length, $8 \mathrm{~cm}$; width, $4 \mathrm{~cm}$ ) and interposed. Two new suitable ostia from the rectangular pericardial

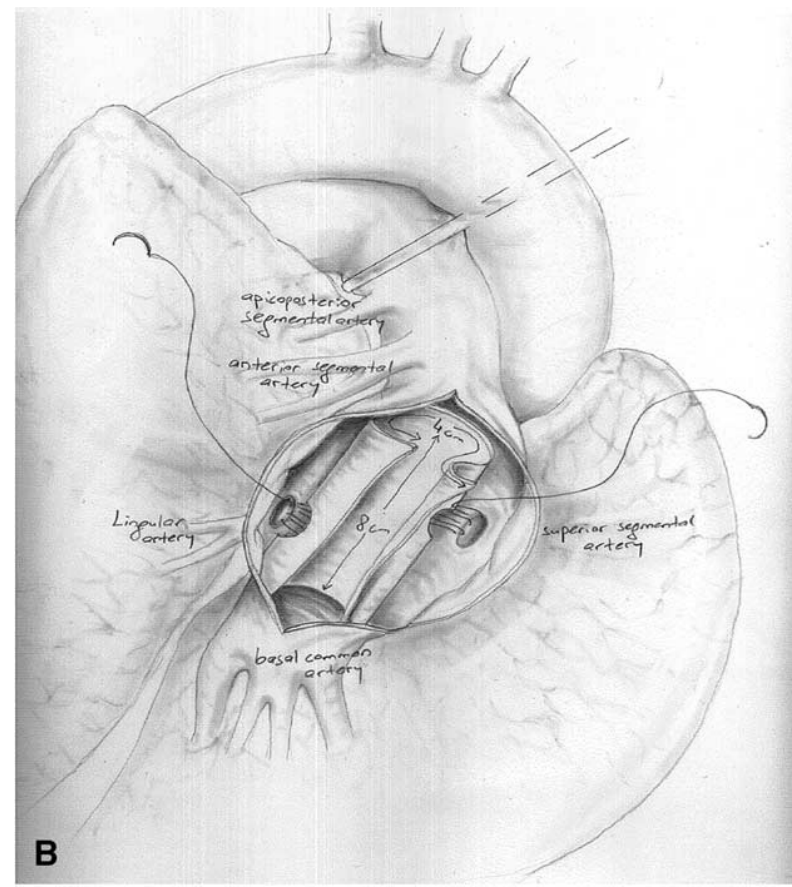

Figure 2B. Use of graft inclusion technique with heterologous pericardial patch $(8 \times 4 \mathrm{~cm})$.

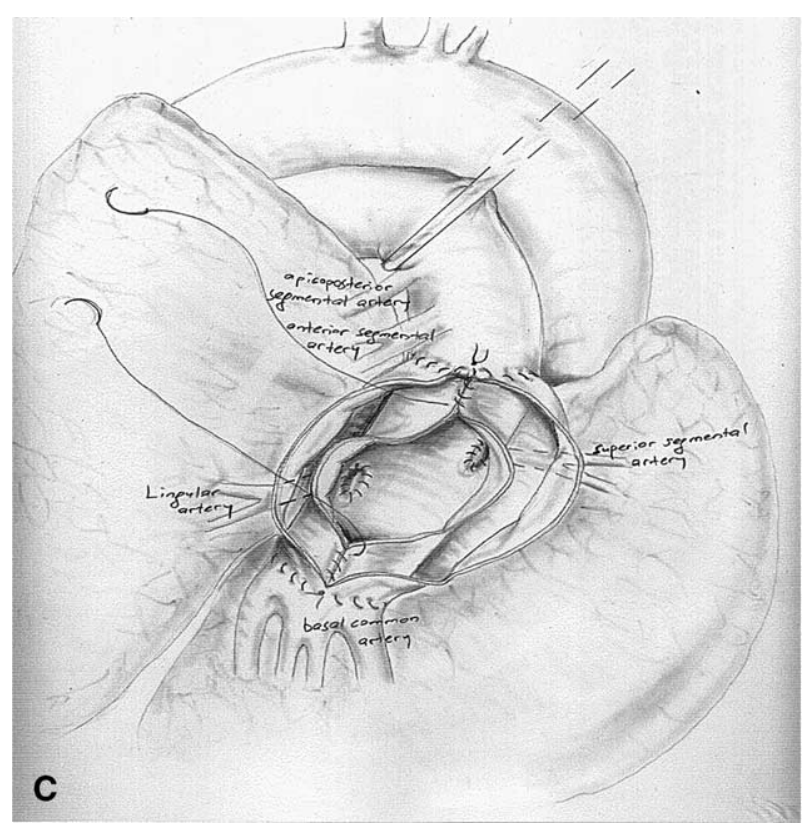

Figure 2C. Completion of anastomoses and elimination of the left pulmonary artery aneurysm.

patch, according to native anatomical localization for the lingular artery of the left upper lobe and the superior segmental artery of the lower lobe, were cut out. One of these new ostia of the pericardial patch was anastomosed end to side with the 


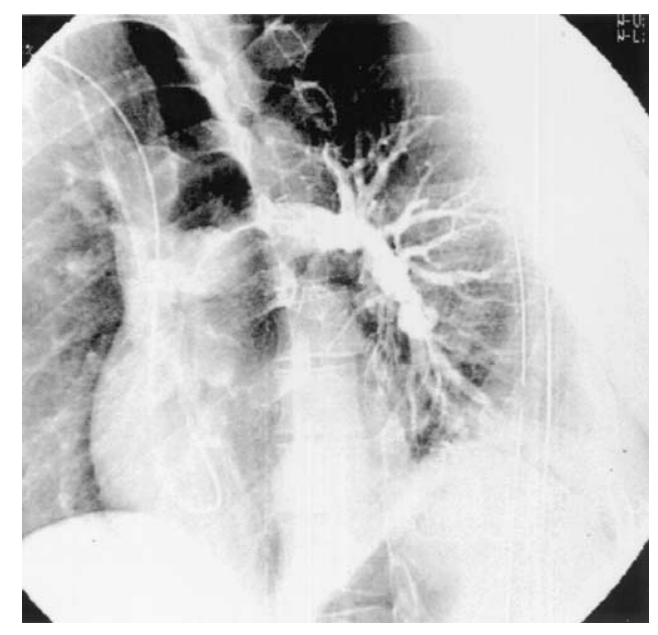

Figure 3. Selective postoperative angiogram of the left pulmonary artery.

native ostium of the lingular artery of the upper lobe and another one end to side with the native ostium of the superior segmental artery of the lower lobe. The proximal anastomosis of the pericardial patch was performed end to end with the left pulmonary artery below the branches of the apicoposterior and anterior segment in circumferential form. The distal anastomosis of the pericardial patch was complete, with the left common basal artery above the bifurcation to the basal segmental arteries of the left lower lobe in circumferential form in an end-to-end manner. The length edges of the pericardial patch are sewn together in a rotund figure-like vessel prosthesis. Finally, deairing through the release of the clamp of the left pulmonary artery was completed. After the release of the clamps of both left pulmonary veins, the extracorporal circulation was terminated. Finally, the entire graft was covered with residual aneurysmatic tissue.

\section{Results}

Postoperative therapy included anticoagulation with coumarin, as well as continuation of prednisone and azathioprine. On the 14th postoperative day, the patient was to be released. However, sudden renewed hemoptysis originating from the right lower lobe occurred, and emergency resection of the right lower lobe was performed through a right posterolateral thoracotomy. After an uneventful 14-day postoperative course, the patient was released to a rehabilitation center. The selective postoperative angiography of the pulmonary artery (Figure 3 ) shows reconstruction with perfusion of all segmental arteries. The patient was in New York Heart Association functional class I at 17 months' follow-up.

\section{Discussion}

Aneurysmectomy, ligation, segmental resection, lobectomy, ${ }^{3}$ or pneumonectomy ${ }^{4}$ are the preferred modes of therapy of intraparenchymal aneurysms of the pulmonary artery. Various surgical procedures are described in the literature for aneurysms of the extraparenchymal pulmonary artery with pulmonary valve disease, including interposition of a valved conduit ${ }^{6}$ and implantation of a pericardial Y graft. $^{7}$ A brief review of the literature ${ }^{8,9}$ emphasizes the necessity of resection to prevent fatal rupture.

The bronchial arteries arise from the systemic circulation and account for approximately $1 \%$ of the cardiac output. After clamping of the left pulmonary artery and both of the left pulmonary veins in our patient, invasive pressure measurements of the left pulmonary artery demonstrated values of $25 \mathrm{~mm} \mathrm{Hg}$, which was a sign that the backflow of the bronchial artery continues. The aim of the use of the extracorporal circulation was the prompt transfusion of the suctioned blood and the support of the systemic circulation of the patient. The systemic arterial blood pressure throughout cardiopulmonary bypass was maintained at a level of at least $100 \mathrm{~mm} \mathrm{Hg}$. The duration of the extracorporal circulation was 101 minutes. Without use of extracorporeal circulation, possible outcomes are bleeding and the death of the patient. As we discovered with cardiac surgery and pulmonary thromboendarterectomy, there is a continued backflow of the bronchial arteries. For this reason, venting of the left ventricle is necessary in cardiac surgery. Even the pulmonary thromboendarterectomy dissectors are developed, which allows simultaneous suction of blood from the pulmonary arteries. ${ }^{10}$

Because of a thrombosis risk in the lower pressure system, we used a biologic material as the vascular graft. Anticoagulation with coumarin was continued for 6 months, until endothelialization of the vascular graft was completed.

At least $50 \%$ of the pulmonary perfusion with normal physiologic ventilation is required to maintain sufficient ventilation and perfusion for the oxygen requirement of the body. If pulmonary artery pressure is less than $40 \mathrm{~mm} \mathrm{Hg}$, then $50 \%$ perfusion and ventilation should exist after pneumonectomy with a normally functioning contralateral lung. After a pneumonectomy, a lobectomy of the contralateral lung is no longer compatible with life. If a lobectomy of the contralateral lung was performed in patients with a pneumonectomy, hypoxemia developed through the loss of the ventilated perfused parenchyma and acute right heart failure developed through increased pulmonary artery pressure after the loss of the pulmonary perfusion like an acute cor pulmonale. Under these circumstances, the residual pulmonary parenchyma is not sufficient for the physiologic ventilation and perfusion to maintain oxygenation and right ventricular function. These conditions lead to the death of the patient.

In a systemic disease with involved lungs, such as Behçet disease, vasculitis can appear. This progressive disease through the immune complex has no effective therapeutic option. Immunosuppressive therapeutics, such as azathioprine, cyclophosphamide, and chlorambucil, can be effective in the acute phase. Despite medical therapy, pulmonary artery aneurysms in both lungs can occur and are the complication due to progressive vasculitis, as observed in our patient. In the literature, the treatment of these aneurysms was parenchymal resection of the lung. In our case this would imply left pneumonectomy. However, after this procedure, lobectomy of the right lower lobe is no longer a therapeutic option. Thus, in the face of the bilateral changes demonstrated in our patient, we considered interposition of the left pulmonary artery with implantation of the segmental arteries to be warranted. The parenchyma resections are palliative therapeutic options to the treatment of the complication of these systemic diseases. Through these, an intrabronchial rupture is treated and prevented. In such a 
systemic disease, the parenchyma sparing is advantageous from a prognostic view, especially because a function restriction of the lung in the progressive course is conceivable.

We described a patient and his surgical treatment, in which we used the lifesaving parenchyma-sparing operation. We believe that replacement of the pulmonary artery for aneurysms of the left pulmonary artery, as well as for aneurysms of the right pulmonary artery, in the intraparenchymal and intersegmental portion over the fissure of the lung is possible. This operation must be performed during extracorporal circulation because there is excessive back bleeding from the bronchial arteries. To our knowledge, we present the first successful interposition of the left pulmonary artery with implantation of the segmental arteries as a lung parenchyma-sparing procedure for pulmonary aneurysms.

We thank Ms Barbara Junghähnel from St.-Johannes-Hospital Dortmund for her drawings of the operation technique.

\section{References}

1. Butto F, Lucas RV Jr, Edwards JE. Pulmonary artery aneurysm. A pathologic study in five cases. Chest. 1987;91:237-41.
2. Tami LF, McElderry MV. Pulmonary artery aneurysm due to severe congenital pulmonary stenosis: case report literature review. Angiology. 1994;45:383-90.

3. Tuzun H, Hamuryudan V, Yildirim S, et al. Surgical therapy of pulmonary arterial aneurysm in Behçet disease. Ann Thorac Surg. 1996;61:733-5.

4. Fukai I, Masaoka A, Yamakawa Y, et al. Rupture of congenital peripheral pulmonary aneurysm. Ann Thorac Surg. 1995;59:52830 .

5. Slavin RE, de Groot WJ. Pathology of the lung in Behçet disease. Case report and review of the literature. Am J Surg Pathol. 1981; 5:779-88.

6. Barbero-Marcial M, Baucia JA, Jatene A. Valved conduits of bovine pericardium for right ventricle to pulmonary artery connections. Semin Thorac Cardiovasc Surg. 1995; 7:148-53.

7. Jacob JL, Garzon SA, Machado NC, et al. Pulmonary artery aneurysm. Report of two cases. Arq Bras Cardiol. 1989;53:33-7.

8. Arom KV, Richardson JD, Grover FL, et al. Pulmonary artery aneurysm. Am Surg. 1978;44:688-92.

9. Ungaro R, Saab S, Almond CH, et al. Solitary peripheral pulmonary artery aneurysms. Pathogenesis and surgical treatment. J Thorac Cardiovasc Surg. 1976;71:566-71.

10. Daily PO, Dembitsky WP, Daily RP. Dissectors for pulmonary thromboendarterectomy. Ann Thorac Surg. 1991;51:842-3.

\section{Chondrosarcoma arising in the trachea: A case report and review of the literature}

Mary Maish, MD, and Ara A. Vaporciyan, MD, Houston, Tex

$\mathrm{P}$

rimary malignant tracheal tumors are rare, accounting for only $0.2 \%$ of all malignancies of the respiratory tract. We present a case of tracheal chondrosarcoma in a 78-year-old man and review the literature.

\section{Clinical Summary}

A 78-year-old white man had a 3-month history of progressive shortness of breath with exertion. He did not have fever, cough, chills, night sweats, or hemoptysis. His primary care physician initially attributed his symptoms to worsening chronic obstructive pulmonary disease and treated him with inhalers and oral steroids. As his symptoms progressed, the patient became increasingly

\footnotetext{
From the Department of Thoracic and Cardiovascular Surgery, The University of Texas M. D. Anderson Cancer Center, Houston, Tex.

Received for publication May 12, 2003; accepted for publication May 28, 2003.

Address for reprints: Ara A. Vaporciyan, MD, 1515 Holcombe Boulevard, Box 445, Houston, TX 77030-4009 (E-mail: avaporci@notes.mdacc. tmc.edu).

J Thorac Cardiovasc Surg 2003;126:2077-80

Copyright $\odot 2003$ by The American Association for Thoracic Surgery

$0022-5223 / 2003 \$ 30.00+0$

doi:10.1016/S0022-5223(03)00949-8
}

bedridden, with dyspnea at rest, and he developed significant weight loss. He also began to experience episodic hoarseness. This symptom progression prompted further evaluation and he had a chest radiograph and then computed tomography (CT), which revealed a noncalcified mass in the lower third of the trachea with near compete obstruction of the lumen. An extratracheal extension of the mass was also present. The patient was transferred to our institution.

The patient was taken to the operating room where flexible and rigid bronchoscopy demonstrated a firm, white, nonfriable endotracheal mass emanating from the right side of the membranous trachea and obstructing $80 \%$ of the tracheal lumen. Endotracheal resection was performed via the rigid bronchoscope to provide an adequate airway. A postoperative CT scan confirmed the improved airway (Figure 1). Pathologic examination of the surgical specimen revealed a type I chondrosarcoma. The patient recovered uneventfully and was sent home for 3 weeks of intensive physical and nutritional therapy. He then underwent definitive resection.

The surgical approach utilized a right posterolateral thoracotomy, and the thorax was entered through the fourth intercostal space. A fourth intercostal muscle flap was harvested. The trachea was exposed anteriorly and posteriorly, and the mass was circumferentially dissected, with 5-mm margins proximally and distally. The tumor was well encapsulated, and both the right vagus and the left recurrent laryngeal nerve were identified and spared. A right 